\title{
Case Report: \\ Congenital Thymic Cyst in an Iraqi Child
}

\author{
NADIM HADDAD, M.D.*; SUHAILA SHAMSE-ELDEN TAHIR, DIM, M.Sc.** and \\ IMAN HASSAN, M.D.*** \\ The Department of Thoracic \& Vascular Surgeon, College of Medicine, Kirkuk University*, Directory of Health** and \\ The Department of Pediatric, Azadi Teaching Hospital***, Kirkuk-Iraq
}

\begin{abstract}
Background: A nine months female child presented with dyspnea was diagnosed by third author applying echocardiography who discovered a large thymic cyst. The diagnosis was confirmed by CT scan; the patient was operated on by the first author applying median sternotomy with smooth post operative recovery and complete absence of symptoms.

Aim of Study: We intended to report this rare case worldwide so that to throw light on every case with mediastinal cyst to include it in the differential diagnosis, and to be kept in mind always during investigating such a case.
\end{abstract}

Key Words: Thymus - Median sternotomy - Kirkuk-Iraq.

\section{Introduction}

CONGENITAL cyst in the mediastinum is one of the causes of mediastinal masses, and the thymic cyst is one of these entities, yet it is a rare condition and usually not included in the differential diagnosis especially in children [1].

The patient was 9 months female, presented by her parents to the Pediatric Consultation Clinic in Azadi Teaching Hospital, Kirkuk by the history of shortness of breath for few weeks, on concentration on other related systems, there was no cough, no abnormal audible breath sound (Wheeze), no fever or difficulty with swallowing.

The patient was seen by many physicians and was managed as asthmatic bronchitis, with little response. Concerning other systems, there was no relevant points in the history.

Correspondence to: Dr. Suhaila Shamse-Elden Tahir, Directory of Health, Kirkuk-Iraq
On examining the patient, she was mildly dyspnic, no pallor or cyanosis, the heart rate was $110 / \mathrm{min}$, the respiratory rate $30 / \mathrm{min}$, there were no flaring of nose or chest retraction, no strider, not grunting, no accessory muscles use and no alteration in the alertness.

The chest X-ray was normal, so it raised the suspicion of having cardiac disease. Echocardiography was performed to the patient, a large anterior mediastinal cystic lesion was seen, and the heart was normal structurally.

The further more sophisticated method to confirm the diagnosis was the CT scan that revealed a large anterior mediastinal cystic lesion with high suspicion of congenital thymic cyst. As is Fig. (1).

The patient was referred to the Department of Thoracic Surgery in the hospital, and the decision was made for the removal of the cyst.

The patient was prepared for the operation in the next day in Azadi Teaching Hospital in Kirkuk and the operation was performed by the first author under general anesthesia through median sternotomy approach. As in Fig. (2).

A large cystic lesion was discovered just behind the sternum covering the whole field anterior to the pericardium and the thymus. Fine and Sharpe dissection was performed in attempt to separate the cyst from the pericardium, thymus, pleura and major vessels in the mediastinum. As in Figs. $(3,4)$.

The cyst was removed intact, drain was left in the mediastinum, and the sternum and the wound was closed in layers. As in Fig. (5). 


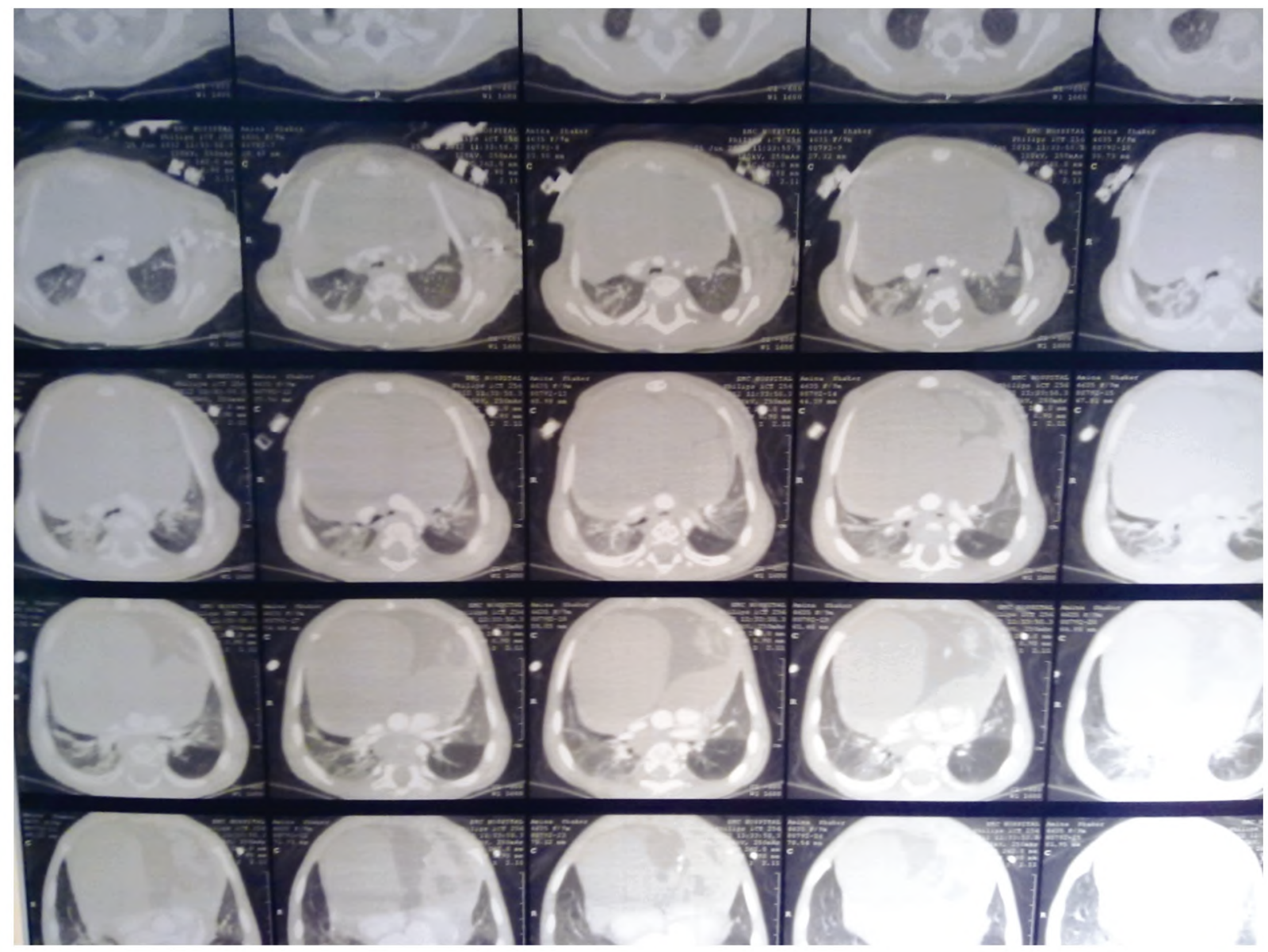

Fig. (1): CT scan of showing anterior mediastinal cystic lesion.

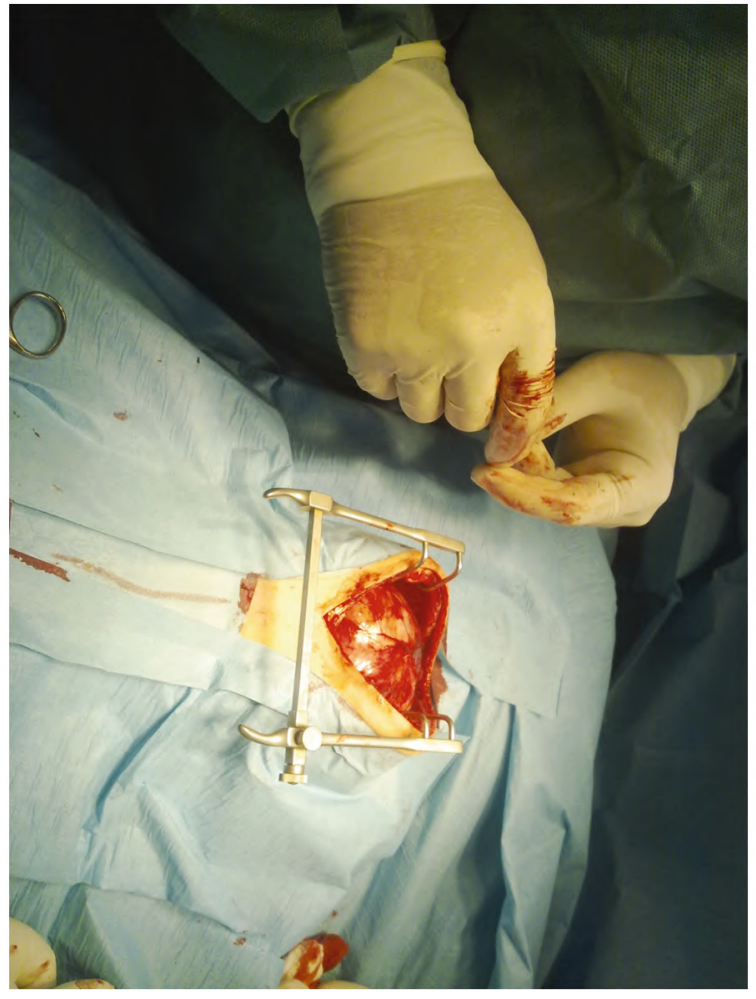

Fig. (2): Median sternotomy.

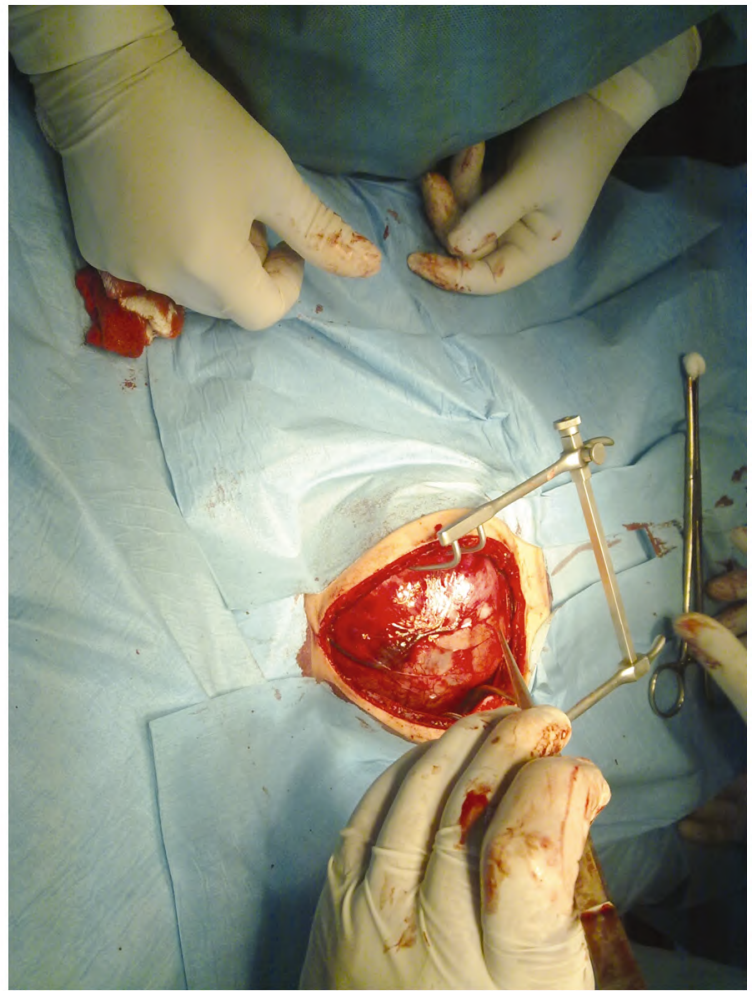

Fig. (3): Separation of the cyst from the pericardium, thymus, pleura and major vessels in the mediastinum. 


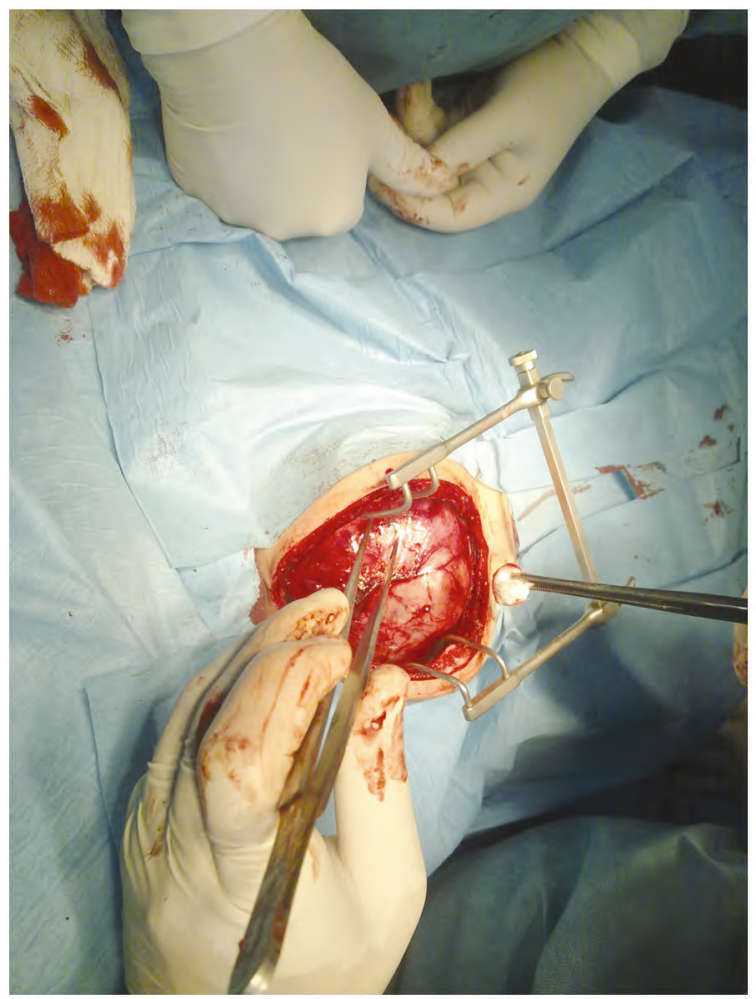

Fig. (4): Separation of the cyst from the pericardium, thymus, pleura and major vessels in the mediastinum.

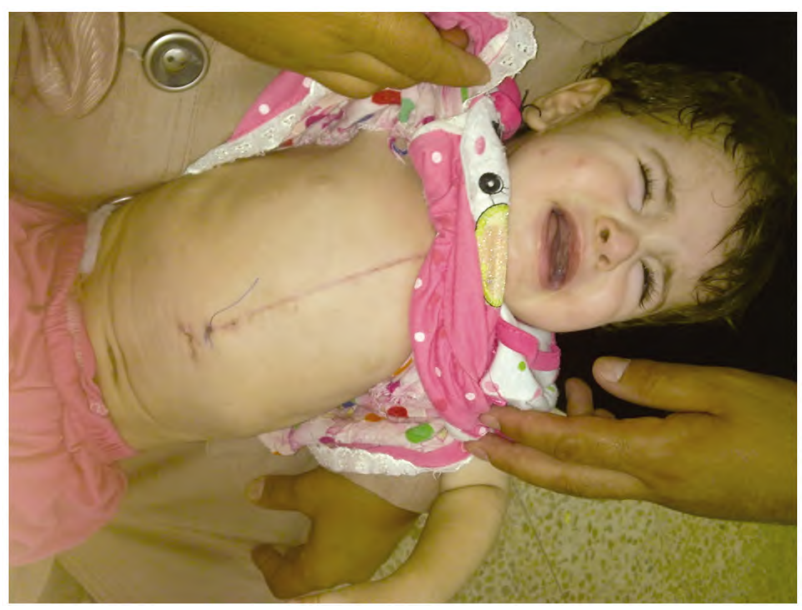

Fig. (6): Post-operative follow-up.

The patient discharged home in the fifth postoperative day with smooth post-operative followup.

The final diagnosis was proved by histopathological study being congenital thymic cyst.

\section{Discussion}

Thymus is regarded as central organ of the lymphoid system in infancy. There are three entites of thymic mass; the first is thymic cyst; the second is ectopic cervical thymus and the third is cervical thymoma.

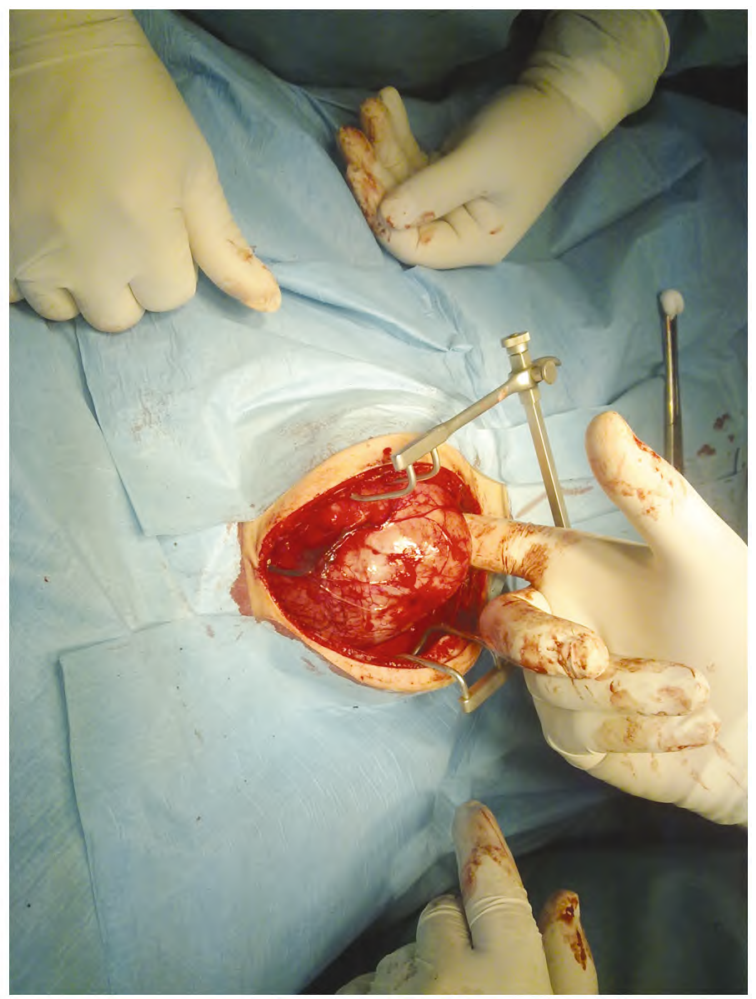

Fig. (5): The cyst was removed intact.

The underlying mechanism of development of cervical thymic cyst remains controversial, yet two favored explanations are suggested;

The first is the persistence of thymopharngeal tract (congenital) and the second is degeneration of hassall's corpuscles, within ectopic thymic remenance (acquired) [2]

Thymic gland originated from the third and fourth pharyngeal pouch with the inferior parathyroid gland.

The thymic gland congenital anomalies are the sequel of the arrest in the descent of the gland or failure of involution. These cysts can be seen at any level from the mandible to the mediastinum, and about half of them continuous with mediastinal thymus [3]

The highest incidence of thymic cyst is discovered in the first decade of life. Which related to the fact that the residues of the thymus are larger during the time before puberty [4]

The benign cyst represent $1 \%$ of the anterior mediastnal masses, these cysts are usually unilocular, lined with squamous or small columnar cells, containing clear fluid, in contrast to acquired cyst which are multilocular containing chocolate colored or gelatinous materials [5] 
Congenital thymic cyst may present as pressure effect on other organs like recurrent laryngeal nerve, esophagus, pericardium, lungs, compression of the right ventricle and transudative pleural effusion.

Sahhar et al., defined a case of ten days old boy with strider and respiratory distress [6]

The CT scan features of benign mediastinal cyst are: A smooth oval or tubular mass with a well defined thin wall that enhances after intravascular administration of contrast materials, homogenous attenuation, no enhancement of cystic content and no infiltrations to the adjacent mediastinal structures [7]

\section{References}

1- PEREZ A.C., De ARVELHO L.C., CAPUCI H.H., et al.: Thymic cyst: An option in the differential diagnosis of cervical mediastinal thymus. Braz J. Otorhinolaryngel., (76C4): 538, 2010.

2- SANEI M.H., BERJIS N. and MESBAH A.: Cervical thymic cyst, a case report and review of the literatures. JRMS. (11C5): 339-42, 2006.

3- MAHMODLON R., GHEIBI S., NARGESI A.A., et al.: Symptomatic cervical thymic cyst. A case report and literature review. Compr. Red., 4 (3), 2013.

4- OZBEY H., RATSCHEK M. and HOLLWORTH M.: Cervical mediastinal thymic cyst. report of a case. Surg. today, 35: 1070-2, 2005.

5- TERMINELLA A., CASAMANO G., VESTA I., et al.: Huge congenital thymic cyst with microscopic thymoma. World Journal of Cardiovascular Surgery, 3: 111-3, 2013.

6- SABZI F., EIZADI B., JAVID M., et al.: Congenital thymic cyst in the retro cava position. A case report. Iran red crescent Med. J., (17ca): 159-84, 2015.

7- JEUNG, H.Y., G.B., GENGI A., et al.: Imaging of cystic mass of the mediastinum. RNSA radiography. Vol. 22: I 2002

\section{الكيس الصعترى الولادى فى طفلة عراقية}

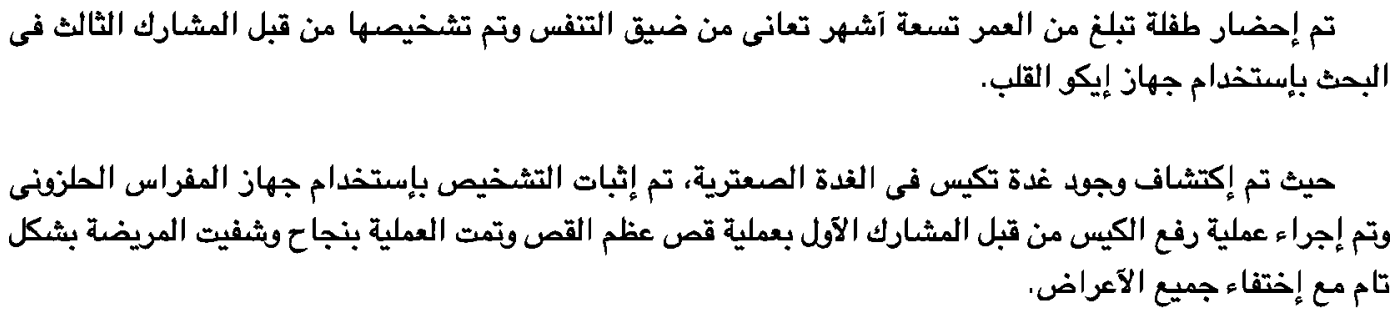

